\title{
A Comparative Ethnoarchaeological Analysis of Corporate Territorial Ownership
}

\author{
Jacob Freeman, John M. Anderies \\ Department of Anthropology, The University of Texas at San Antonio, One UTSA \\ Circle, San Antonio, TX 78256 Email: Jacob.Freeman@utsa.edu \\ School of Human Evolution and Social Change, School of Sustainability, Arizona State \\ University Email: m.anderies@asu.edu
}

\begin{abstract}
Ecological models are a fundamental tool that archaeologists use to clarify our thinking about the processes that generate the archaeological record. Typically, arguments reasoned from a single model are bolstered by observing the consistency of ethnographic data with the argument. This validation of a model establishes that an argument is reasonable. In this paper, we attempt to move beyond validation by comparing the consistency of two arguments reasoned from different models that might explain corporate territorial ownership in a large ethnographic dataset. Our results suggest that social dilemmas are an under appreciated mechanism that can drive the evolution of corporate territorial ownership. When social dilemmas emerge, the costs associated with provisioning the public goods of information on resources or, perhaps, common defense create situations in which human foragers gain more by cooperating to recognize corporate ownership rules than they lose. Our results also indicate that societies who share a common cultural history are more likely to recognize corporate ownership, and there is a spatial dynamic in which societies who live near each other are more likely to recognize corporate ownership as the number of near-by groups who recognize ownership increases. Our results have important implications for investigating the coevolution of territorial ownership and the adoption of food production in the archaeological record.
\end{abstract}

Keywords: Ownership, Human ecology, Hunter-gatherer, Agriculture, Food production, Coevolution 


\section{INTRODUCTION}

Basic economic theory tells us that as resources become more dense and predictable, rational individuals in competition with each other maximize their fitness by claiming ownership and defending their ownership claims over resource locations (Brown, 1964; Dyson-Hudson and Smith, 1978). This model of economic defensibility is foundational to explanations for territorial ownership in hunter-gatherer societies (Baker, 2003; Cashdan, 1983; DysonHudson and Smith, 1978; Kaplan et al., 2009; Kelly, 1995; Sealy, 2006; Smith, 1988, 2012; Thomas, 1981; Zeder, 2012) and, increasingly, archaeological explanations for the adoption of agriculture (Bettinger et al., 2009; Bowles and Choi, 2013; Smith, 2012; Zeder, 2012). Despite the clear importance of the model of economic defensibility, arguments reasoned from this model have not been evaluated in comparison with arguments reasoned from alternative models that might also explain why foragers adopt rules of territorial ownership. Such a comparison of arguments is epistemologically healthy. Observations consistent with a single argument tell us that the argument is reasonable, but, in complex systems, almost any reasonable argument will fit data to one degree or another. The key question is: Which argument best fits the available data?

In this paper, we compare the relative consistency of two arguments that might explain the evolution of corporate territorial ownership in huntergatherer societies. These two arguments follow from the logic of the model of economic defensibility and a recent model of forager-resource coevolution (Freeman, 2014; Freeman and Anderies, 2012) that comes out of a deep intellectual tradition in resource economics and community ecology (Clark, 1976; Noy-Meir, 1975). The goal of this comparison is to develop a more robust corpus of knowledge about the mechanisms that may lead foragers to adopt the corporate ownership of territories. In turn, we argue that this knowledge provides a basis for asking more nuanced questions about the archaeological record. In what follows, we define the basic problem of corporate territorial ownership. Next, we describe the model of economic defensibility (MED) and the foraging effort model (FEM). We describe these two models to elucidate why the models suggest different arguments for the evolution of territorial ownership. Finally, we conduct an analysis of corporate ownership rules in a global ethnographic database in an attempt to identify which argument is more consistent with the data.

The results of our analysis indicate that the emergence of social dilemmas 
drives up the costs associated with the exchange of information on the predictability of resources within a territory. This mechanism plays a heretofore under appreciated role in the adoption of rules of corporate ownership by populations of foragers. Our results also suggest that while ecological conditions have an immediate impact on the costs and benefits of territorial ownership, cultural transmission may have a longer-term effect on corporate territorial ownership. In a positive feedback loop, once foragers in particular locations begin to recognize territorial ownership, this recognition of new social rules exerts pressure on nearby groups to also adopt territorial ownership. Why this is the case requires further investigation. Our results have important implications for recent arguments in the archaeological literature that the adoption of territorial ownership by foragers was a necessary condition for the adoption of agriculture.

\section{MODELS, ARGUMENTS \& TERRITORIAL OWNERSHIP AMONG FORAGERS}

By the term "model" we mean the abstract description of relationships between variables in a system. Models may be verbal descriptions or formal equations, but in either case, they are tools for clarifying one's thinking about the interaction of variables in a system. The model of economic defensibility (MED) and foraging effort model (FEM) are similar models in that they both describe the relationships between the density of resources, competition for resources, and the predictability of resources. As such, we view these models as tools that help one propose explanations for some set of phenomena. By explanation we mean an argument that states the conditions under which a phenomenon will and will not occur; in this case, the phenomenon is corporately recognized territorial ownership. We belabour the above distinction to point out that our analysis is an attempt to compare alternative arguments that might explain the evolution of territorial ownership. The two arguments were arrived at via an analysis of the MED and FEM respectively, but it is conceivable that arguments other than the two we describe below could be reasoned from an analysis of each model.

\subsection{Territorial ownership}

We define territorial ownership as the social norms that define access to a territory for some and limit access for others. Territories for our purposes are collections of habitats in which foragers might reside, and habitats are 
collections of patches that contain many different types of resources. In anthropology, the ownership of territory is often conceptualized as a continuum from open access at one pole to private property at the other pole (Smith, 1988). Here, we start from a different premise. Rather than a continuum, we suggest that hunter-gatherers have nested sets of contingent norms that define the ownership of resources and territories. This means that multiple rules of ownership may exist simultaneously and apply at different levels of social organization. Which rule is activated depends on context and negotiation.

The most basic rule of "ownership" in forager societies is that individual foragers own the resources that they harvest. Steward (1938, p. 253) describes this norm among the Western Shoshoni, "But once work had been done upon the products of natural resources they became the property of the person or family doing the work." In any society there are multiple competing norms that may apply in a given situation, so just because we propose that hunter-gatherers have a basic norm of 'you harvest it, you own it' does not mean that this norm will always be activated. Sharing norms, in the correct context, may supersede the individual ownership norm of 'you harvest, you own'. For example, when Hadza foragers harvest berries outside of their overnight camps, the rule of 'you harvest, you own' applies; however, if berries are transported back to camp, individuals share their harvests more frequently (Marlowe, 2010, p. 237). There is a huge literature on when and why individuals share. Our point here is not to address this literature, we simply note that there is a basic norm of individual ownership of harvested food, but whether or not this norm is activated depends on competing norms of sharing and reciprocity. In societies in which the only ownership rule in place is the contingent: 'you harvest, you own' rule, territories are open access, while individual resources are contingently owned once harvested.

Our concern in this paper is to assess competing explanations of the processes that lead hunter-gatherers to adopt rules of corporately recognized territorial ownership. Practically, this means the adoption of a rule by social groups in which access to a territory is limited for individuals who are not members of the social group. This is a situation that requires cooperation; the exclusion of non-group members may be enforced by territorial defense (i.e., attacking intruders) or requiring participation in a ritual or ceremony to gain access to a territory. Both of these activities are common ways of insuring compliance with a social norm in human societies (Bicchieri, 2006). For example, Ray (1963, p. 201) tells us that territorial "boundaries were 
precisely defined and understood by the Modoc and transgression meant war." This is clearly a case of a group defined territorial boundary. However, among the Modoc, the contingent rule of 'you harvest, you own' still applied. Individuals and families, for example, were the recognized owners of the roots and tubers that they dug for winter storage (Ray, 1963, p. 163), but cases of illness would invoke norms that put pressure on families to share their food supplies. Other examples of a corporately recognized rule of territorial ownership include the Tiwi, among who "the band was the land-owning, workaday, territorially organized group which controlled the hunting, the food supply and the warfare" (Hart and Pilling, 1965, p. 13). According to Steward (1938, p. 255), the Owens Valley Paiute "were distinctive for their band ownership of hunting and seed territories."

In a small number of hunter-gatherer societies recorded ethnographically, we see three or possibly more norms of ownership over territory and resources in coexistence. Corporately recognized norms of ownership, as those described above, may be augmented by additional norms that define the ownership of particular locations for smaller segments of society within corporately recognized territories. In this case, we see stable rights vested in smaller segments of a group to control access to particular locations. These rules exist alongside the rules that define group access and limits to territory, as well as the most basic rule of 'you harvest, you own'. To illustrate, among the Clear Lake Pomo Gifford (1923, p. 81) writes,

"Rattlesnake Island, on which was located the village of Elem, was communal property, and any villager might help himself to the acorns or other products of the island; not so on the mainland, however, which to the north, east and south was claimed by Elem, but was not communal property. It was divided into nearly ninety named tracts, owned by the various families of Elem."

Although the 90 tracts were owned by family groups, rights were in the oak trees on the land. Outside of the harvest season for acorns, individuals could transgress the boundaries of these tracts to hunt for game, and the hunter retained rights to the game (though other sharing norms might have existed upon transporting the game back to the village). In this example, we see three simultaneously present norms of resource and territorial ownership. The rule of 'you harvest, you own' is the most inclusive allowing access to resources for all members of Elem, but is only applicable to certain resources 
in certain seasons, in the example above, deer. The rule of corporate ownership defines rights for members of Elem to exclude members of other social groups. Finally, the family ownership rule defines access to particular oak groves for some families of Elem and limits access for others. Importantly, this rule depends on the corporate ownership rule, because individuals from "competing" villages could transgress the oak grove of a family without fear of reprisal if the corporate norm was not in place. It is the corporate norm that creates a context in which families can claim the ownership of specific oak groves within the larger territory.

In sum, there is a clear difference between the contingent 'you harvest, you own' rule and the ownership of territory by a social group. In the ownership of territory by a social group, individuals must engage in collective action to "own" territory. Individuals must also patrol or monitor for intruders and potentially sanction intruders to maintain the integrity of territorial boundaries for everyone in a group.

\section{THE MED}

Although there are other approaches, evolutionary anthropologists and archaeologists have relied on the MED to develop an explanation for territorial ownership by social groups in hunter-gatherer societies (Kelly, 1995; Thomas, 1981; Smith, 2012; Zeder, 2012). The MED was introduced into cultural anthropology by Dyson-Hudson and Smith (1978). Dyson-Hudson and Smith (1978) argue that the ownership of territories by humans is the outcome of a continuum of trade-offs between the density and predictability of resources and the fitness benefits derived from territorial ownership and defense by individuals. In this argument, the density and predictability of resources determines the the amount of territory that an individual needs to secure resources. Holding competition for an area equal, in locations where resources are dense and predictable, the area required for an individual to maximize her rate of energy gain should decline (Dyson-Hudson and Smith, 1978). In turn, the net benefits of patrolling and defending a territory from challengers should increase and individuals who adopt such behaviours can increase their fitness relative to individuals who do not. Thus, territorial ownership provides a net fitness benefit for individuals as resources become more dense and predictable in space and time, assuming there are a sufficient number of intruders to defend a territory against (Baker, 2003; Dyson-Hudson 
and Smith, 1978; Kelly, 1995; Smith, 1988, 2012; Zeder, 2012). For clarity of presentation, we call this the area reduction argument.

Dyson-Hudson and Smith (1978) use Steward's data on ethnographically observed hunter-gatherers in the Great Basin of North America to evaluate their argument for the evolution of ownership and suggest that their argument fits the data. The fit between Steward's observations and their argument is a data matching exercise. The exercise establishes that the area reduction argument is reasonable; however, it does not actually test the argument in a substantive way because there is no alternative. One of the potential short comings of the Dyson-Hudson and Smith (1978) data matching exercise is that there is a range of demographic and technological variation among the societies discussed. For example, the Owens Valley Paiute bands are said to own territory because they exploit dense and predictable grass seeds which are made dense and predictable by irrigation. This begs the question of whether ownership preceded irrigation or whether irrigation preceded ownership? The answer matters because some other process may have led to the adoption of band ownership, which, in turn, provided an incentive for irrigation, which, in turn, made grass seeds more dense and predictable. The sample of societies in their analysis is not large enough to answer such questions.

In a very influential assessment of the area reduction argument Cashdan (1983) studied the territoriality of hunter-gatherers living in the Kalahari Desert of Southern Africa. Contrary to her expectations reasoned from the area reduction argument, Cashdan (1983) found that foragers more tightly controlled access to their territory as rainfall and, by inference, resources became more unpredictable within a territory. Specifically, the !Ko more tightly controlled access to their territory via what Cashdan calls social boundary defense. This occurs when individuals engage in rituals and/or ceremonies to ask permission to use a territory. Cashdan's work (1983) illustrates that rules of territorial ownership by social groups may be activated in two ways: 1) by sanctioning or perimeter defense or 2) by social integration through rituals in which individuals from different social groups recognize their common interest in recognizing territorial ownership. These findings are well supported by research in behavioural economics on norm activation (Bicchieri, 2006).

At first glance, Cashdan's results contradict the area reduction argument. However, Smith (1988) and Kelly (2013, p. 161-162) argue that her results provide a context for extending the area reduction argument rather than a critical test (and we concur). They argue that, holding competition equal, 
where resources are dense but vary in such a way that the productivity of "competing" group's territories are anti-correlated, there is a net fitness benefit for individuals to engage in territorial ownership based on social boundary defense. The key is that the productivity of competing group's territories are anti-correlated, which provides an incentive for individuals in competing groups to recognize each other's ownership claims (Cashdan, 1983; Smith, 1988). This is a perfectly reasonable extension of the area reduction argument, but it has not been evaluated against other arguments nor has a data matching exercise been conducted with respect to this possibility. Again, in this example the sample of societies studied was very small. A larger sample might reveal that the !Ko are a very interesting outlier.

\section{THE FEM}

The FEM formally studies the feedback between the fraction of an individual's time budget devoted to the harvest of resources and the mean resource density of an area over time. The model is a tool that facilitates the study of how individual foraging decisions scale-up to effect the dynamics of resources at the system level, and, in turn, how resource dynamics feedback down to impact the costs and benefits of individual foraging strategies. Our study of this feedback process suggests to us an alternative argument that may explain the adoption of territorial ownership by social groups. For clarity of presentation, we call this the common pool resource dilemma argument. More details on the model are available in the supplemental file and in the following sources: Freeman (2014) \& Freeman and Anderies (2012). The FEM describes a baseline forager-resource system. By this we mean that a resource location is treated as open access with the simple rule of 'you harvest, you eat.' We use our knowledge of the model's dynamics to develop an argument that describes the conditions under which a baseline system might change and individuals might cooperate to adopt a corporate rule that restricts access to a territory.

The key dynamic in the FEM that is relevant here is as follows. Holding all other parameters equal, as the mean productivity of resources in a habitat declines or population density increases, foragers maintain a consistent supply of food because each individual works a little bit harder (i.e., spends more time harvesting food) to meet their desired amount of food (Freeman and Anderies, 2012). However, this strategy of working a bit harder generates a particular kind of non-linear behaviour in the system known as multiple 
stable states. In this case, one stable state is a productive or benign state (also known as an attractor). The other stable state or attractor is a degraded state. In their simplest form, attractors define collections of stable equillibria that characterize the long-run evolution of a system. An equilibrium is a unique solution to a set of equations. When we refer to states or attractors, we are referring to properties of the model. Real forager-resource systems constantly change but may settle into regimes that approximate stable states, as we use the term here (Scheffer and Carpenter, 2003). The concept of multiple stable states provides a powerful paradigm to help us think about change in real systems as potentially dichotomous and punctuated rather than smooth and continuous (see e.g., Anderies et al., 2002; Janssen et al., 2003; Lade et al., 2013; Lever et al., 2014; May et al., 2008; Scheffer et al., 2012; Staver et al., 2011).

In the Freeman and Anderies (2012) model, in the productive state, the foraging strategy of meeting resource needs with minimum effort is tenable (i.e., harvest as efficiently as possible until food needs are met, then stop and devote the remainder of one's time budget to other activities). In the degraded state this is not possible. A forager must constantly look for food just to stay alive, and a forager's time budget is exhausted just to subsist (this is analogous to a "poverty trap" in economics). When the FEM is characterized by both a productive and a degraded stable state, every forager is susceptible to short-term environmental variation (like a drought or immigration event) that can flip a forager-resource system from the productive to the degraded state. For example, a drought could cause the productivity of food in a habitat to drop below the long-term mean productivity of the habitat; this, in turn, induces individuals to increase the time they spend harvesting food (Freeman and Anderies, 2012, p. 431-432) causing a "flip" into the degraded state. Importantly, the presence of multiple stable states means that this flip from productive to degraded circumstances can be punctuated (i.e., occur much more rapidly than a model without multiple stable states would permit) and difficult for individuals to anticipate because of the uncertainty generated by the delayed feedback between past foraging decisions and the current state of a resource base (Freeman and Anderies, 2012, p. 431).

\subsection{The common pool resource dilemma argument}

In an environment where forager-resource systems are susceptible to flipping into a degraded state, foragers face a commons dilemma. In the FEM, habitats are open access. As long as the productive state is the only stable 
long-run equilibrium in the system, treating a habitat as open access works just fine. However, holding all other parameters constant, once the mean productivity of a habitat decreases or population density increases past a critical threshold, the degraded state emerges. Now, depending on how ecological conditions vary, foragers might occupy a productive or a degraded state. The commons dilemma arises because it is in each forager's interest to work hard enough to obtain their desired amount of food from a habitat, but the effects of this scale-up and create the risk that all foragers in the system will not achieve their desired level of food due to a shock (like a drought) that induces the system to flip into a degraded state. As noted above, such a transition may be very difficult to anticipate. When individuals cannot anticipate such a transition, the ability to know where other foragers are located on the landscape becomes paramount, because they are a potential perturbation which may generate a critical transition from the productive to the degraded state.

Our basic argument is that the emergence of common pool resource dilemmas where none had previously existed stresses the ability of foragers to update their information about the state of resources in an environment. In such an ecological setting, individuals have a choice: Either continue with business as usual and risk experiencing localized "tragedies of the commons" or cooperate to manage the pressure on various resource locations temporally, limiting who, when and where resources may be harvested via more investment in ownership. This second option decreases the amount of effort that individuals must invest in the collection of information and increases the reliability of the information that individuals have on the location of others. Although it is costly to develop and maintain ownership rules, such rules decrease the complexity of information that individuals must collect and interpret to reliably plan how to use a landscape and avoid the fitness costs associated with a tragedy of the commons (see also Supporting Information).

For example, in their study of the role of information in Kua foraging strategies, Hitchcock and Ebert (2006, p. 146-147) state:

"prior to the seasonal breakup of hunter-gatherer groups, the localities to be occupied by various family units were surveyed. The resources available in the area to which people might move were assessed carefully, as were the current states of occupancy, use and sentiments about resource sharing among groups that had rights to that area. Once this process was complete, the rela- 
tive advantages and disadvantages of the alternative places were exhaustively discussed prior to reaching a consensus on what options should be persued."

This passage illustrates the central importance of information collection and interpretation to plan out a sequence of movements in space and time to gain access to resources. Our argument is that once common pool resource dilemmas are characteristic of a forager-resource system, this scout, discuss, and then execute residential movements strategy is stressed. The emergence of multiple stable states in the potential habitats of a group's territory makes the time necessary to scout and discuss where to move next longer and, depending on how unpredictable shocks are that hit a territory, this process of decision making may be less effective at planning out residential movements. That is, people make a decision about which habitat it is best to move into, but end up in a 'bad spot' (i.e., a degraded harvest state and need to unexpectedly move on). These mechanisms, (more time required to get information and less reliable information) provide an incentive for foragers to adopt strategies for reducing these costs. In this argument, the ownership of territory regulates the movement of foragers in and out of a territory and is beneficial to each individual because it reduces the costs associated with obtaining reliable information on the quality of resource locations.

To revisit Cashdan's (1983) excellent paper, perhaps the reason the !Ko most restrict access to their territory is explained by our argument. The !Ko live in an environment where the mean rainfall is lower and inter-annual variation in rainfall is higher than the other Bushmen group's that Cashdan (1983, p. 51) investigated. This suggests that a) the !Ko are more susceptible from year-to-year to realizing a common pool resource dilemma than the other groups and b) the uncertainty associated with the distribution of resources is high. In short, the !Ko live in a territory where there is more stress on the ability of individuals to process information about their ability to move between habitats and find the anticipated resources relative to the other groups in Cashdan's study. Thus, it is in every individual's interest to cooperate to recognize territorial ownership and control the flow of foragers from other groups into the territory. It is in the interest of foragers from other groups to recognize such claims because to shirk them would give the !Ko ample reason not to provide information on the quality of resource locations that the "intruders" might want to use. We believe this is a reasonable argument. However, we want to do more than establish that an argument is 
reasonable. Our goal is to use data to evaluate which argument is more reasonable or if neither argument adequately explains patterns in a large sample of ethnographic cases.

\section{PREDICTIONS}

The purpose of this section is to summarize the predictions that follow from the logic of the area reduction and common pool resource arguments. We highlight predictions that are mutually exclusive because these are key to determining which argument is most consistent with the data.

\subsection{Area reduction argument}

The area reduction argument suggests eight basic predictions (see Table 2 below for a summary). First, holding all else equal, as the density of resources in an environment increases, the likelihood that hunter-gatherer groups are recorded to corporately own territories should increase. This should occur because as the density of resources increases, individuals should need less area to harvest food and the net benefit of territorial ownership should increase. In forager societies, the density of exploited resources is a function of diet (i.e., the foods that foragers primarily target) and the growth rate (biomass growth per unit time) of resources. As biomass accumulates at a faster rate, resource density should increase and the likelihood that hunter-gatherers own territories should also increase.

Second, in terms of diet, some argue that aquatic resources (fish and shell fish) provide dense and predictable resources (Hamilton et al., 2007; Sealy, 2006) and this allows individual foragers to decrease the size of their territory. If this assertion has merit, the reduction in territory size should increase the net benefit of territorial ownership. Holding all else equal, we might then expect that an increase in the exploitation of aquatic resources increases the likelihood that hunter-gatherer groups own territory.

Third, the predictability of resources within a territory is a function of intrinsic variation in the basic physical inputs that determine the productivity of resources, such as temperature and rainfall. Again, centris peribus we expect that as the inter-annual coefficient of variation associated with rainfall increases, terrestrial resources become less predictable and the likelihood that hunter-gatherers recognize the corporate ownership of territories declines. Following the logic of the area reduction argument, this should occur because it is costly for individuals to invest in the ownership of habitats that are 
unpredictably devoid of food and, therefore, the net benefit of owning a territory declines as resources become less predictable (Dyson-Hudson and Smith, 1978).

Fourth, following the dynamics proposed by the MED, we expect that the density and predictability of resources interact to amplify the area requirements for individuals to obtain food. In other words, given a sufficient level of competition, as the density of resources goes up in conjunction with an increase in the predictability of rainfall, we expect that the positive effects of resource density and predictability on the likelihood of ownership increase in strength as resources become simultaneously more predictable and dense. We expect this because the territory needed per forager should decline at an amplifying rate as the resources within territories become more dense and predictable, allowing foragers to maximize their fitness through corporate control of reliable and productive territories.

Fifth, the area reduction argument suggests that ownership should only occur when there is someone to defend a territory against (Brown, 1964). Holding other factors constant, as population density increases, the likelihood that foragers have someone to defend resources against should increase, and foragers should make and defend ownership claims. Sixth, accounting for the interaction of competition and resource density, we also expect to see a threshold effect. Where competition is very low, we should observe that resource density has a negligible effect on the likelihood of ownership. However, as completion increases, we should observe an increasingly strong and positive effect of resource density on the likelihood of ownership. Seventh, the same prediction also applies to the predictability of resources within a territory. At low levels of competition, the effect of resource predictability is negligible because their is no one to defend against. As competition increases, an increase in the predictability of resources should have a positive and increasingly strong effect on the likelihood of ownership.

Finally, in human societies competition may take the from of attacks made by coalitions through warfare and raiding. All else being equal, we expect that foragers are more likely to own territories as the frequency of warfare/raiding increases, again, provided there are dense and predictable resources worth owning. If such resources were unavailable, then foragers may simply cede control of marginal territory and move elsewhere. We also suspect that there might be similar interaction effects between warfare, resource density and the predictability of resources as those described above in conjunction with population density. 


\subsection{Common pool resource argument}

As above, the phrase "holding all else equal" applies to each of the predictions below, and we predict the potential interaction effects suggested by the dynamics of the FEM. First, as the productivity of terrestrial resources declines, the likelihood that hunter-gatherer groups own territories should increase. The dynamics of the FEM indicate that as the growth rate of resources declines, a forager-resource system becomes more vulnerable to environmental variation that may generate a flip from the productive to degraded harvest state for all foragers (i.e., a tragedy of the commons). This should create an environment that favours the selection of rules of ownership by foragers as one way to isolate a territory from indirect competition and reduce the information processing costs associated with choosing where to locate in space and time to harvest food. Please note that this prediction is the opposite of what we expect based on the area reduction argument.

Second, a related argument in the hunter-gatherer literature is that huntergathers increase their use of aquatic resources in response to the depression of terrestrial resources (Binford, 2001; Keeley, 1995). Given that, as noted above, aquatic resources are potentially productive and reliable resources, then as terrestrial resources become less productive relative to population density, the emergence of multiple stable states and associated risks may stimulate individuals to shift toward aquatic resources and invest in isolating these resources from competition. In essence, the combination of aquatic resource use and ownership could begin to decouple individual foragers from the risk of getting flipped into a degraded harvest state in a terrestrial resource system. Thus, we expect a positive relationship between the use of aquatic resources and the adoption of territorial ownership. Importantly, we expect the positive effect of fishing to occur in tandem with a negative association between the productivity of terrestrial resources and territorial ownership.

Third, the common pool resource argument suggests that increasingly unpredictable terrestrial resources creates an environment in which the benefits outweigh the costs of adopting territorial ownership. Holding all else equal, an increase in the variance of resource productivity should increase the chances that a group of foragers experience a flip from a productive to a degraded state. For example, any environment will have a long-term mean rainfall. As the variance associated with inter-annual rainfall increases, the intensity of dry periods and the ability to predict which years will be dry should decline. In this situation, the benefits of adopting and following own- 
ership rules that coordinate the use of territories should outweigh the costs because ownership decreases the effort needed to collect information on where other foragers are at on the landscape. In turn, more effort can be devoted to dealing with the rainfall induced risk of a system flipping into the degraded state, for example, investing in water management.

Fourth, we expect that as population density increases, foragers are more likely to formally own territories. Here, just as with declines in the productivity of resources, as population density increases, resource depletion causes a commons dilemma to emerge in a forager-resource system. The commons dilemma, in turn, is indicative of a system in which foragers are sensitive to flips between a degraded and productive states caused by environmental variation, like droughts or unexpected immigration events. Thus, as population density increases and depletion creates a commons dilemma, we expect that the net benefits of holding exclusive space increases because individuals can better estimate their risk of ending up in a degraded state when they can know with certainty where other foragers are likely to locate on a landscape (Charnov et al., 1976; Wilson et al., 1994).

Fifth, as with the MED, we expect warfare to have a positive association with the likelihood that hunter-gatherers recognize corporate ownership. If foragers invest in corporate ownership institutions to help avoid a tragedy of the commons, then increased investment in warfare is likely necessary to protect and defend ownership claims. In other words, individuals invest in ownership to isolate resource locations from competition. In turn, this also requires cooperating to defend those ownership claims from outsiders through things like retaliatory raiding and attacking perceived intruders. In this case, we would expect the warfare does not interact in a significant way with other parameters to increase the likelihood of ownership because it is a consequence of the adoption of corporate ownership.

Following the dynamics of the FEM we expect the following interaction effects between competition, resource density and predictability. Sixth, as resources become more dense and simultaneously more predictable, we should observe an increase in the strength of the negative effect of resource density on the likelihood of ownership. Seventh, as the density of resources declines, the strength of the negative effect of resource density on ownership should increase as population density increases. Following the common pool resource argument, a simultaneous decline in productivity and increase in population density should amplify the possibility that foragers will realize a common pool resource dilemma and get flipped into a degraded state. Thus, there 
will be a non-linear increase in selective pressure on foragers to recognize corporate ownership. Finally, as the predictability of resources increases, the strength of the positive effect of population density on ownership should decline. Again, the less variable the productivity of a territory from year-toyear, the less stress there is on the scout, discuss and execute a sequence of movements strategy discussed in the FEM section. Similarly, a simultaneous increase in population density coupled with a decrease in the predictability of resources should amplify the stress put on the ability of foragers to scout, discuss and execute a sequence of residential moves.

\section{Materials and Methods}

The ethnographic data used here were compiled from Binford (2001) ( $\mathrm{n}=339$ societies). The observations made on each society were collected from primary sources written by ethnographers working independently and at different times and places (Binford, 2001). No data are perfect, and the data used here are no different. However, the large sample size allows researchers to check the consistency of competing arguments with data, even if the ability to falsify an argument is uncertain. These data have been used productively in a similar manner (e.g., Fenner, 2005; Grove, 2009, 2010; Grove et al., 2012; Hamilton et al., 2007, 2009). The data set provided by Binford was collected independently of the arguments assessed in our analysis.

To assess territorial ownership among hunter-gatherer societies, we use the variable recoded by Binford (2001, p. 426) called OWNERS. This variable is a description of territorial ownership, in terms of the presence of group recognized rules of ownership discussed above. There are four categories.

Category 1) None reported, but all groups have identity and practical links to both land and resources. There may be strong attachments in the form of persons seen as stewards of both land and lore. There are, however, no local group claims on the area in general (Binford, 2001, p. 426).

None reported in this case does not mean the absence of any kind of ownership, only that definite rules for including and excluding members of social groups from a territory are not reported in ethnographic sources. For example, speaking of Shoshoni informants from Eastern California, Steward (1938, p. 73) states that they "all denied any form of family, village, or band ownership of seed lands. Although people from certain localities habitually 
exploited the same areas, anyone was privileged to utilize territory ordinarily visited by other people." Category 1 is a context in which territories are open access and the basic 'you harvest, your own' rule is contingently activated.

Categories 2 and 3 describe very similar contexts of ownership.

Category 2) The local group definitely claims exclusive use rights, over resource locations, residential sites, and the home range, in general. There may be a further set of claims among the households or lineages within the local group-special trees, shell beds, etc. Category 3) Local group claims hunting areas, dominant animals, fishing sites and animal drive locations. Administration may be by a leader. Some resources may be said to be clan or lineage owned.

The main difference between categories 2 and 3 is that Binford differentiates the particular resource locations (e.g., a fishing site) over which groups recognize corporate ownership that restricts rights of access. He also stipulates that rights of access may be administered by a group leader in category 3 . However, the ability to make a distinction between categories 2 and 3 is suspect, in our view. For example, the Modoc described earlier are an example of category 3. The Nomlaki are an example of category 2 in the Binford data set. Goldschmidt (1951, p. 332-333) states of Nomlaki ownership:

"Ownership of land resided in the olkampa. Each olkampa usually owned a valley territory and another area in the mountains. Since the control and usage rested in the hands of the village chieftain, informants occasionally made reference to individual ownership."

He goes on to state that personal ownership could be claimed over the seasonal products of trees and fishing locations (Goldschmidt, 1951, p. 333). For our purposes, the fact that the distinction is fuzzy between these two categories is not as salient as the fact that categories 2 and 3 represent definite norms of ownership either by a settlement group or a band. This is a major difference from category 1 because it requires social groups to cooperate to legitimize access and the denial of access either through shared social conventions or through attacking intruders.

Finally 28 societies in the data set are listed as category 4),

Elite ownership of land and resources. In addition, there may be family claims to particular resource locations. Resource patches 
may be owned by a family and can be given away, inherited or disposed of within the group.

The major difference between categories $2 \& 3$ vs. 4 is the presence of inherited claims of ownership. In categories 2 and 3, social groups recognize their right to exclude others from their lands, but they do not recognize the ability of individuals or families to inherit and dispose of smaller segments of territory nested within the group's territory or home range. Again, Goldschmidt's (1951, p. 333) Nomlaki informant states "everyone knows the trees that were his own property. There was no inheritance of trees." This stands in contrast to the Clear Lake Pomo, discussed earlier, who are an example of a category 4 society. Speaking of small tracks of forest nested within the larger village owned territory, Gifford (1923, p. 83) states: "Land was normally owned by males and transmitted to their male offspring."

We collapse the $O W N E R S$ variable into a binary indicator variable for the presence or absence of norms that define the corporate ownership of a territory. Category 1 above is indicative that territories are open access settings (indicator value of 0 ). In our terms, category 1 societies have the basic social norm of 'you harvest, you own', which, of course, is contingently activated based on factors such as the resource being harvested, where consumption takes place and the strength of sharing norms (see Hadza example earlier). Categories 2-4 indicate that territories are owned by social groups, either bands or villages. Again, in our terms, there are two nested rules: 1) 'you harvest, you own' at the individual level and 2) the norm of corporate rights to a territory. We have experimented with separating category 4 from categories $2 \& 3$ and running a multinomial logistic regression. We find that this does not change our results. However, it is difficult to interpret the multinomial logistic regression in part because of the small sample of only 28 category 4 societies. We welcome follow-up analyses that look at different ways to measure the presence of a group recognized norm or territorial ownership at the village or band level. All groups in categories 2-4 have such a basic norm, category 4 societies simply have additional norms that define the inheritance of smaller segments of territory within the group's larger territorial unit.

[Table 1]

Five variables are used to evaluate our predictions (Table 1). Net primary productivity data were obtained from Grieser and colleagues (Grieser et al., 2006) from their study of global patterns of net primary productivity for the 
Food and Agriculture Organization. Net primary productivity is a rate of biomass growth (see Odum and Barrett, 2002; Porter and Marlowe, 2007). We assume that the higher the rate of biomass growth in an environment, the higher the rate of growth for biomass that is useful as food. Of course, the relationship between the growth of biomass and biomass useful as food may be more complex. Ultimately, NPP is constrained toward the poles by temperature. However, in equatorial areas, different vegetation communities with large differences in standing biomass can have very similar values of net primary productivity. It is in equatorial areas where uncertainty about the relationship between NPP and food growth is probably highest. Understanding the relationship between the rate of biomass growth and the growth of biomass useful as food is an important direction for research to improve comparative studies. The coefficient of inter-annual variation was calculated here from global, gridded precipitation means calculated between 1950 and 2000 at a one decimal degree scale (Beck et al., 2004). The grid cell nearest to the centre of each group's territory was used to estimate the coefficient of variation in inter-annual rainfall experienced by each society. We assume that the higher the inter-annual coefficient of variation in rainfall, the more that the productivity of terrestrial biomass varies unpredictably from year-to-year.

The frequency of warfare is estimated here by an ordinal warfare variable that estimates the frequency of fighting and raiding (Binford, 2001). 1) No organized competition. Success in armed conflict is not an accepted male role in the overall life of the people. 2) Conflict is continually present on an on-again/off-again basis. Accelerated raiding (i.e., tit-for-tat raiding that becomes progressively more encompassing) is not a normal condition. 3) Conflict is more common than in category two and there are unprovoked attacks on intruders. There is planned and tactically executed raiding on other groups not necessarily in the context of revenge or feuding. 4) Conflict is common in the region, but it may flare up to major proportions periodically. Goals are more commonly to plunder and take land or resources. 5) All the properties of category four but with the additional feature that such conflict is sustained and results in long-term expansion of groups at the expense of others.

\subsection{Methods}

We use multiple, binary logistic regression to relate the joint probability that a corporate ownership norm is either recorded or not recorded, i.e., 


$$
P\left(\text { Ownership }=1 \mid x_{1}, \ldots x_{i}\right)=\frac{1}{\left(1+e^{-\left(\alpha+\sum_{i} b_{i} x_{i}\right)}\right)}
$$

where $x_{1}, \ldots x_{i}$ refers to a given set of explanatory variables, $\alpha$ is a constant and $b_{i}$ is a coefficient associated with each variable. Equation 1 can be transformed into a general linear model using the so-called logit link function, such that

$$
\ln \left(\frac{\hat{p}}{1-\hat{p}}\right)=\alpha+\sum_{i} b_{i} x_{i}
$$

where $\hat{p}$ is the joint probability that a hunter-gatherer group is recorded to recognize a corporate ownership norm, given a set of explanatory variables.

The coefficients in equation 3 describe the effect that a change in an explanatory variable has on the log-odds that a hunter-gatherer group is recorded to own territory. We assume that groups of hunter-gatherer societies are, a priori, independent of model parameters and are equally likely to have been recorded by ethnographers to own territory. We use model selection methods to evaluate the sign and relative importance of the explanatory variables (Johnson and Omland, 2004). We base our model selection and the analysis of the relative importance of the explanatory variables on the Akaike Information Criterion (AIC). AIC is a measure of the fit and complexity of a statistical model. The analytical procedure for estimating the sign and relative importance of each explanatory variable was conducted using the $R$ computing environment ( $\mathrm{R}$ Development Core Team, 2008).

The procedure we used to estimate the sign and relative importance of the explanatory variables is as follows. First, the MuMin $\mathrm{R}$ package was used to calculate all potential binary logistic regression models for the set of independent explanatory variables on the response variable of territorial ownership. For example, when analysing the full data set of 339 societies, there are five potential explanatory variables (population density, warfare, net primary productivity, fishing and the coefficient of variation in rainfall). Thus, this procedure results in 32 candidate logistical regression models, including a "null" model that only includes an intercept. Second, each model is ranked according to its AIC value from lowest to highest AIC. The best model is the statistical model with the lowest AIC (i.e., the model that best balances fit and complexity). This ranking allows one to calculate the change in $\mathrm{AIC}, \Delta_{i}$, as $A I C_{i}-\min A I C$, where $A I C_{i}$ is the AIC of a candidate model 
under consideration and $\min A I C$ is the AIC of the model that best balances fit and complexity.

Third, standardized Akaike weights, $w_{i}$ are calculated for each candidate model. Akaike weights summarize the likelihood that a given model is the best approximate fit, given the data. The Akaike weight is calculated by first determining the likelihood that a model is the best approximation to the data, which conveniently is: $L($ model $\mid d a t a) \propto e^{0.5 \Delta_{i}}$. Next, the the sum of the likelihoods of all regression models is calculated. Then, the Akaike weight is simply $w_{i}=\frac{e^{0.5 \Delta_{i}}}{\sum_{r=1}^{R} e^{0.5 \Delta_{r}}}$. The Akaike weight is used here to define a $95 \%$ confidence set of models; that is, the set of models that is likely to contain the regression model that is the best fit to the data.

Fourth, the mean regression coefficient and standard error of each explanatory variable included in the $95 \%$ confidence set of models is calculated. The relative importance of each explanatory variable present in at least one regression model of the $95 \%$ confidence set is also calculated. The relative importance of an explanatory variable is simply the sum of the Akaike weights of each model in which a variable is present. For example, if the $95 \%$ confidence set of regression models contains three candidate models, each model with a weight of $0.40,0.30$ and 0.25 , respectively, and population density is a parameter in the top two weighted models, then the relative importance of population density is $0.70(0.40+0.30)$. If the percent of diet obtained from fishing were present in all three models, its importance measure would be $0.95(0.40+0.30+0.25)$. The summed Akaike weights estimate the relative likelihood that a parameter is included in the best regression model (i.e., the model closest to truly representing the data). In this hypothetical example, fishing is 1.37 times more likely than population density to have a true effect on the ownership of territory. The closer a variable's importance measure is to 1 , the more likely the variable is to have a true effect on the response variable, given the data and candidate set of regression models.

\section{PRELIMINARY ANALYSIS}

Table 2 summarizes our expectations for the effects of ecological variables on the likelihood of ownership reasoned from the area reduction and common pool resource dilemma arguments, respectively. To assess these predictions we first conduct a preliminary analysis of interaction effects and the potential for bias introduced by autocorrelation. 


\subsection{Interaction effects}

The above procedure allows us to calculate what we call a baseline set of regression outputs (see Table S1 \& S2). These baseline outputs treat each explanatory variable as an independent variable. However, as noted (Table 2), we expect that the explanatory variables may interact in predictable ways. To evaluate interaction effects, we followed the above procedure including all potential interaction effects of a variable in our analysis. For example, we first evaluated the effects of interacting the coefficient of variation in rainfall with each other parameter. This gave us 9 parameters (warfare, population density, fishing, net primary productivity, the coefficient of variation in rainfall and C.V. rainfall interacted with each of the first four parameters) to run on our response variable (ownership). We recorded any interaction effect with a summed Akaike weight greater than or equal to 0.60 for the $95 \%$ confidence set of models as evidence of a potentially important interaction. Next we did the same thing for net primary productivity, which gave us 8 parameters to run on our response variable ( 8 because we had already checked the interaction effect of C.V. rainfall and net primary productivity). Again, we recorded any interaction effect with a summed Akaike weight greater than or equal to 0.60. We followed this procedure for each variable. Our analysis indicates that two interaction effects are most likely (a summed Akaike weight $\geq 0.60$ ) to partly determine the ownership of territory, C.V. rainfall interacted with population density and net primary productivity interacted with population density. Thus, our preliminary analysis indicates that net primary productivity and C.V. rainfall are very likely to interact with population density and effect the likelihood of ownership while the other variables in the analysis are highly unlikely to interact.

Next, we run our four step procedure (outlined above) running all five independent parameters and the two most likely interaction effects on the probability of ownership. We call this output our "full regression output" (see Table S3 and S4). The best regression model in this analysis includes all seven parameters, the five independent parameters and our two most likely interaction parameters. However, when we examine the best regression model in detail (i.e., the model with the lowest AIC), we observe two things. 1) A high degree of multicollinearity between population density and our two interaction parameters (Figure S5). This is a potential problem because multicollinearity can increase the standard error associated with a coefficient and bias the sign of a coefficient. Given that 0 falls within the 95\% confidence limit of the coefficient associated with population density, 
we remove population density as an independent parameter to deal with the problem of excessive multicollinearity. 2) The coefficients for C. V. rainfall and net primary productivity also overlap with zero, so we remove these two variables as independent parameters.

[Table 2]

Below, we run our four step procedure to obtain what we call our "efficient regression output." In this analysis, there are four parameters: warfare, the percent of diet from fishing, C.V. rainfall interacted with population density and net primary productivity interacted with population density (Tables S5 \& S6). To assess the effects of the interaction terms in the efficient regression output, we use effect plots. The effect plots allow us to observe the effect of population density on the probability of ownership holding the coefficient of variation in rainfall and net primary productivity equal. This is important because interaction effects can be non-linear and such processes can be missed by just observing the summary coefficient associated with an interaction parameter (Fox and Hong, 2009).

\subsection{Autocorrelation}

The use of logistic regression assumes that the ethnographic cases are independent. However, societies who live near each other or share a common cultural history may be interdependent due to cultural transmission (Galton's problem). By cultural transmission we mean a "process of social reproduction in which the culture's technological knowledge, behavior patterns, cosmological beliefs, etc. are communicated and acquired" (Hewlett and Cavalli-Sforza, 1986, p. 922; see also Boyd and Richerson, 2004). This is a potential issue because when the observations in a logistic regression are not independent, the coefficients associated with parameters may be biased upward, making it difficult to assess the consistency of our arguments with the data. Further, cultural transmission processes might create feedbacks between the adoption of corporate ownership and the likelihood that neighbours adopt corporate ownership rules. Such feedbacks could be an additional process that helps explain the presence of corporate ownership in the ethnographic record.

To evaluate the potential for autocorrelation due to spatial proximity and/or shared cultural histories, we ran our four step procedure to evaluate the effects of warfare, the percent of diet from fishing, C.V. rainfall interacted with population density and net primary productivity interacted with population density on the likelihood of ownership. The best model includes all 
four parameters (Table S5). We then ran a Moran's I test for autocorrelation on the residual deviances using a weighted distance matrix based on spatial distance and a matrix calculate based on linguistic difference (as an estimate of shared cultural history). In both cases, we identified an extremely weak but significant level of autocorrelation. Moran's I was $0.12(p \leq 0.05)$ for our test of spatial autocorrelation and was $0.01(p \leq 0.05)$ for our test of network autocorrelation. This suggests that we need to account for spatial and network autocorrelation to fairly evaluate the area reduction and common pool resource arguments.

To insure that our parameters are as free from bias a possible due to autocorrelation, we use a two stage regression model to incorporate the endogenous effect of spatial and linguistic proximity into our analysis (Dow, 2008). We first lag our ownership variable (i.e., multiply our dependent variable vector by a distance matrix) using a weighted distance matrix that combines both measures of spatial distance and linguistic difference to account for vertical and horizontal cultural transmission. We combined these matrices following the procedure outlined by (Dow, 2008, p. 412) (see supplemental file for details). Here, the best combination is a slight weighting toward linguistic relatedness as opposed to pure spatial proximity. Next, we run a linear regression of four instrumental variables on the response variable of ownership lagged by the the weighted distance matrix. Our four instrumental variables are simply $X_{i} W$, where $X_{i}$ is one of our four parameters from our most efficient regression analysis above (warfare, fishing, population density interacted with net primary productivity and C.V. rainfall interacted with population density), and $\mathrm{W}$ is the combined weighted language and distance matrix. We save the vector of our unstandardised residuals from this OLS regression and then run the following logistic regression to account for spatial and network autocorrelation:

$$
\ln \left(\frac{\hat{p}}{1-\hat{p}}\right)=\alpha+\beta W y+\sum_{i} b_{i} x_{i}+\lambda v
$$

here $\beta$ is the coefficient associated with the lagged endogenous binary ownership variable; and $\lambda$ is the coefficient associated with the vector of unstandardised residuals (v) obtained from the stage 1 OLS regression. This should result in coefficients associated with warfare, fishing, population density interacted with net primary productivity and population density interacted with C.V. rainfall that are not biased by autocorrelation processes (i.e., re- 
gression errors that are asymptomatic and normally distributed) (see Dow, 2008, p. 403). Our main results reported below are the output of the second stage regression, and we call these outputs our final regression outputs. A Moran's I test for autocorrelation using our combined distance and language matrix on the residual deviances of the best regression model in the final output indicates that our endogenous lag variable successfully accounts for autocorrelation $(\mathrm{I}=0.001 ; p>0.05)$.

\section{MAIN RESULTS}

Our final regression outputs illustrate two main findings.

1. The data are more consistent with the common pool resource argument than the area reduction argument. This suggests that the emergence of social dilemmas is an under appreciated mechanism that favours the adoption of corporate territorial ownership, though not the only mechanism.

2. There is a "legacy" effect apparent in the data set. Groups who share a common cultural history are more likely to recognize corporate ownership. Further, there is a spatial dynamic in which groups who live near each other are more likely to recognize corporate ownership as the number of near-by groups who recognize such ownership increases.

\subsection{Independent effects}

Table 3 illustrates the mean coefficients, standard errors and summed Akaike weights associated with each variable and interaction term in the 95 $\%$ confidence set of regression models in our final regression output. The endogenous lag variable for the presence and absence of a corporate ownership rule has a positive effect on the likelihood of ownership. This suggests that groups who share a common cultural history and are closer in space to groups who recognize corporate ownership are more likely to do so as well. Consistent with the area reduction argument and the common pool resource argument, warfare and the percent of diet obtained from fishing both have a positive effect on the likelihood of ownership. Finally, the residuals from the stage one OLS regression, which represent the deviance unexplained by cultural transmission and the ecological variables, have a negative effect on the likelihood of ownership. This suggests that there is, as yet, an unaccounted for process that negatively effects the likelihood that societies recognize corporate ownership. 
[Table 3]

\subsection{Interaction effects}

As noted in the methods section, effect plots are needed to interpret the effect of interacted variables on a response variable. Figure 1a illustrates that as population density increases, at a given value of C.V. rainfall, societies are more likely to recognize corporate ownership. Please note that the intercept of each "effect line" increases as the value of C.V. rainfall held constant increases. This indicates that as rainfall, and, by implication, the availability of terrestrial foods, gets more unpredictable, societies are more likely to recognize a corporate ownership rule. This result is consistent with the common pool resource argument but is not consistent with the area reduction argument. Figure 1b illustrates that, holding population density constant, net primary productivity has a negative effect on the likelihood of ownership. Moreover, the strength of the effect (the steepness of each respective curve on Figure 1b) increases as population density increases. This indicates that societies are less likely to recognize the corporate ownership of territory as resources get more dense, holding all else equal, and this is consistent with the common pool resource argument but not the area reduction argument. Finally, Figure 1b demonstrates that, once the deviance explained by the interaction of population density and $C$. V. rainfall is accounted for, population density has a negative effect on the likelihood of corporate ownership at a given level of net primary productivity. This is a pattern not explained by either the area reduction or common pool resource arguments.

[Figure 1]

\subsection{The relative importance of variables}

Table 3 illustrates the summed Akaike weights of the variables in the 95 $\%$ confidence set of regression models. This measure of importance allows us to examine which variables are most likely to determine the likelihood of ownership and, thus, make statements about which variables are most essential to explaining corporate ownership. With importance values of 1 , the spatially lagged ownership variable, warfare and C. V. rainfall interacted with population density are the most essential variables in this data set to explain the likelihood of ownership. With summed weights of 0.72 and 0.58 respectively, the percent of diet obtained from fishing and net primary productivity interacted with population density are 1.32 and 1.72 times less likely to effect ownership, respectively, than the three variables with weights 
of 1 . The implication of this result is that competition, uncertainty in the availability of resources and cultural transmission processes are more likely to effect ownership than the density of terrestrial resources, in this data set.

Table 4 illustrates the deviance explained by each variable in the best regression model (i.e. the model with the lowest AIC). This table is another way to examine the importance of explanatory factors. Again, the data indicate that the endogenous, spatially lagged ownership variable, C. V. rainfall interacted with population density and warfare explain a large proportion of the deviance. Conversely, net primary productivity interacted with population density and fishing explain a low proportion of the deviance. The implication, again, is that changes in population density interacted with C.V. rainfall, warfare and cultural transmission have a larger and more certain effect on the likelihood of corporate ownership than population density interacted with net primary productivity and fishing.

[Table 4]

\section{DISCUSSION \& CONCLUSION}

Our main gaol in this paper has been to compare two different arguments that might explain the evolution of corporate territorial ownership in huntergatherer societies with data. The critical results that tip the balance in favour of the common pool resource argument are: Holding all else constant, as terrestrial resources become less predictable and dense, hunter-gatherers are more likely to recognize corporate ownership (Figure 1). These findings are simply inconsistent with the area reduction argument. However, these patterns are consistent with the common pool resource argument. In this argument, forager-resource systems are sometimes characterized by multiple regimes, such as the productive and degraded harvest attractors described in the FEM section. The rapid and difficult to anticipate transition between such regimes in highly variable environments could provide a powerful incentive for individuals to adopt corporate territorial ownership (see predictions section). We argue that the development of common pool resource dilemmas and the information processing costs associated with such dilemmas to schedule residential movements and reliably access habitats on a landscape is a neglected mechanism that favours investment in formal rules of territorial ownership (Wilson et al., 1994; Charnov et al., 1976). In short, the corporate ownership of territory provides a public good by coordinating where and when individuals harvest resources, and contributing to this public good has 
a net benefit for individuals when common pool resource dilemmas (caused by the emergence of multiple potential harvest regimes) characterize a terrestrial resource base. The implication is that the net benefits of collective action to monitor, sanction and ritually integrate social groups rather than net benefits of defending a territory determined by the area that individuals need to find food is a more important constraint on the evolution of corporate territorial ownership.

Clearly, our results also indicate that we have more to learn. We suggest three directions for future research. First, a provocative result of our analysis is the positive and independent association between warfare and corporate ownership. This relationship may occur because corporate ownership does little good without a commitment to defense, as suggested by the common pool resource argument. However, there is another mechanism that we speculate could also account for this association.

The formal notion of ownership institutions is likely to affect two things for individuals in the case of persistent warfare. 1) Ownership institutions generate boundary rules, in the language of Ostrom (2005), that enable individuals to efficiently monitor and sanction territorial intruders. In this case, ownership is place-based, defines who is a member of a particular territorially defined group, and everyone knows who the outsiders are (for monitoring), as well as how to sanction them (attack them). 2) Corporate ownership could reduce the costs of warfare for individuals by facilitating "diplomatic" solutions or peace making (Kelly, 2000). In this case, social groups who agree to own a territory via collective action provide the public good of common defense and diplomatic relations with other potentially hostile groups. Given that simply moving when attacked is a costly option, warfare or persistent raiding could create a situation in which free riding by one individual (relying on others to provide defense) depletes the ability of a social group to provide for the common defense of a territory. In such a situation, it might pay for individuals to cooperate and recognize norms that define the corporate ownership of territory. Groups who recognize such rules may then out-compete groups through population expansion who do not, expanding their territory due to their superior abilities to cooperate. This is the argument made by Bowles (2009) that warfare and ownership coevolve because warfare creates selective pressure for more effective cooperation at the level of the group (Olson, 1993). In any case, warfare may create a social dilemma that is distinct from a common pool resource dilemma in some situations. The need to provide the public good of common defense or get pushed out of a territory may 
favour the evolution of corporate ownership.

Second, our analysis indicates that, holding other social-ecological variables equal, groups who share a common cultural history are more likely to recognize corporate ownership, and there is a spatial dynamic in which groups who live near each other are more likely to recognize corporate ownership as the number of near-by groups who recognize such ownership increases. Thus, both vertical and horizontal cultural transmission are implicated. This result suggests the possibility that once corporate ownership is adopted, it may persist, even if ecological conditions change. From an archaeological standpoint this is intriguing. Once corporate ownership evolves, such rules may continue to affect the subsistence strategies of individuals, even if ecological conditions change in such a way that we might expect that the net benefits of corporate ownership decline. An important issue for further research is developing an understanding of the mechanisms that favour the horizontal and vertical transmission of corporate ownership rules and how these two processes operate in conjunction to partly determine variation in rules and norms of ownership (Towner et al., 2012).

Finally, more work is needed to develop an understanding of ownership as nested sets of norms. Our results suggest that the area reduction argument does not explain corporate ownership as well as the common pool resource argument. However this does not mean the the model of economic defensibility is not useful. The MED makes two latent assumptions: 1) There is no feedback between the harvest of resources and resource density in a territory over time and 2) collective action is free. Our results indicate that these assumptions are just too simple to understand the evolution of corporate ownership. The MED might be quite useful, however, for understanding the ownership of individual resources in which collective action is not required to defend a resource and ownership decisions are made much faster than the feedback between resource density and resource harvest operates. For instance, principles of the MED have been used to understand investment in hoarding (a kind of individual ownership) vs. sharing or tolerated scrounging (Kelly, 2013; Blurton Jones, 1984) where the latent assumptions of the MED are more likely to be met. Moving forward, we suggest that we need multiple models to understand ownership as nested sets of norms.

\subsection{Implications for the adoption of food production}

Several important papers have recently argued that formal rules for territorial ownership necessarily coevolve with the adoption of food production 
(Bowles and Choi, 2013; Bettinger et al., 2009; Smith, 2012; Zeder, 2012). This argument posits that only when ownership institutions are in place that allow individuals to take a greater interest in futures gains does food production also evolve in a population of foragers. For example, Smith (2012) provocatively argues that the onset of the Holocene led to an increase in the productivity of terrestrial resources and the establishment of resource rich zones at mid-latitudes; in turn, this increase in the productivity of resources contributed to declines in the size of territory needed by foragers to find food and favoured investment in the ownership of territories by individual foragers (Smith, 2012; Zeder, 2012). This argument is based on the model of economic defensibility. An increase in terrestrial productivity deceases the amount of territory that foragers need and creates an incentive for individuals to invest in territorial ownership. Territorial ownership creates an incentive for individuals to invest in food production because the ownership institutions protect the fruits of agriculture from arbitrary expropriation and/or sharing obligations (see also Bowles and Choi, 2013).

A critical result of our study relevant to this argument is that the corporate ownership of territories decreases as terrestrial resources become more dense and/or predictable. The implication is that climate drivers that make terrestrial resources more dense and predictable are not likely to increase the benefits of territorial ownership for individual foragers, holding all else equal. Rather, this situation is likely to create less incentive to formally own territories, holding competition constant. Ownership and the adoption of food production may very well coevolve, but how this process occurs needs closer examination. Our study suggests that the emergence of social dilemmas rather than a reduction in the area necessary per forager to obtain food is a more important mechanism that favours the evolution of territorial ownership.

The model of economic defensibility has organized how archaeologists and ethnoarchaeologists study the evolution of territorial ownership for more than 30 years. This has been a good thing. The model's logic is compelling and leads to a straightforward argument that we have called the area reduction argument. However, the area reduction argument has never been compared with other arguments that might also explain the evolution of corporate territorial ownership. In this paper, we have compared the area reduction argument with an alternative that we call the common pool resource dilemma argument. The common pool resource argument is based on the logic of a non-linear dynamical system that models the feedback between 
foragers and resources. Our results are more consistent with the common pool resource argument. As a consequence, we suggest that the costs of collective action to monitor, sanction and ritually integrate social groups are an under-appreciated constraint on the evolution of corporate territorial ownership.

\section{ACKNOWLEDGEMENTS}

We would like to thank two anonymous reviewers for their time and challenging comments, as well as Peggy Nelson and Michael Barton for helpful comments on previous versions of this manuscript. All mistakes are our own.

\section{References}

Anderies, J. M., Janssen, M. A., Walker, B. H., 2002. Grazing management, resilience, and the dynamics of a fire-driven rangeland system. Ecosystems 5 (1), 23-44.

Baker, M. J., 2003. An equilibrium conflict model of land tenure in huntergatherer societies. Journal of Political Economy 111 (1), 124-173.

Beck, C., Grieser, J., Rudolf, B., 2004. A New Monthly Precipitation Climatology for the Global Land Areas for the Period 1951 to 2000. Vol. Climate Status Report 2004. German Weather Service, Offenbach, Germany.

Bettinger, R., Richerson, P., Boyd, R., 2009. Constraints on the development of agriculture. Current anthropology 50 (5), 627-631.

Bicchieri, C., 2006. The Grammer of Society: The nature and dynamics of social norms. Cambridge University Press, Cambridge.

Binford, L. R., 2001. Constructing frames of reference: An analytical method for archaeological theory building using hunter- gatherer and environmental data sets. University of California Press, Berkeley.

Blurton Jones, N. G., 1984. A selfish origin for human food sharing: Tolerated theft. Ethology and Sociobiology 5 (1), 1-3.

Bowles, S., 2009. Did warfare among ancestral hunter-gatherers affect the evolution of human social behaviors? Science 324 (5932), 1293-1298. 
Bowles, S., Choi, J.-K., 2013. Coevolution of farming and private property during the early Holocene. Proceedings of the National Academy of Sciences 110 (22), 8830-8835.

Boyd, R., Richerson, P. J., 2004. The origin and evolution of cultures. Oxford University Press.

Brown, J. L., 1964. The evolution of diversity in avian territorial systems. The Wilson Bulletin, 160-169.

Cashdan, E., 1983. Territoriality among human foragers - ecological models and an application to 4 bushman groups. Current Anthropology 24 (1), $47-66$.

Charnov, E. L., Orians, G. H., Hyatt, K., 1976. Ecological implications of resource depression. The American Naturalist 110 (972), 247-259.

Clark, C. W., 1976. Mathematical bioeconomics: The optimal management of renewable resources. Wiley, New York.

Dow, M. M., 2008. Network autocorrelation regression with binary and ordinal dependent variables: Galton's problem. Cross-Cultural Research 42, 394-419.

Dyson-Hudson, R., Smith, E., 1978. Human territoriality: an ecological reassessment. American Anthropologist 80 (1), 21-41.

Fenner, J. N., 2005. Cross-cultural estimation of the human generation interval for use in genetics-based population divergence studies. American Journal of Physical Anthropology 128 (2), 415-423.

Fox, J., Hong, J., 2009. Effect displays in $\mathrm{r}$ for multinomial and proportionalodds logit models: Extensions to the effects package. Journal of Statistical Software 32 (1), 1-24.

Freeman, J., 2014. Feedbacks, critical transitions and social change in foragerresource systems. Ph.D. thesis, Arizona State University, Tempe, AZ.

Freeman, J., Anderies, J. M., 2012. Intensification, tipping points and social change in a coupled forager-natural resource system. Human Nature 23, 419-446. 
Gifford, E. W., 1923. Pomo lands on Clear Lake. University of California Publications in American archaeology and ethnology 20, 77-94.

Goldschmidt, W., 1951. Nomlaki ethnography. University of California Publications in American Archaeology and Ethnology 42 (4), 302-443.

Grieser, J., Gommes, R., Cofield, S., Bernardi, M., 2006. New gridded maps of Koeppens climate classification. Food and Agriculture Organization of the United Nations, Rome, http://www.fao.org/nr/climpag/ globgrids/kc_classification_en.asp.

Grove, M., 2009. Hunter-gatherer movement patterns: causes and constraints. Journal of Anthropological Archaeology 28 (2), 222-233.

Grove, M., 2010. Logistical mobility reduces subsistence risk in hunting economies. Journal of Archaeological Science 37 (8), 1913-1921.

Grove, M., Pearce, E., Dunbar, R. I., 2012. Fission-fusion and the evolution of hominin social systems. Journal of Human Evolution 62 (2), 191-200.

Hamilton, M. J., Burger, O., DeLong, J. P., Walker, R. S., Moses, M. E., Brown, J. H., 2009. Population stability, cooperation, and the invasibility of the human species. Proceedings of the National Academy of Sciences of the United States of America 106 (30), 12255-12260.

Hamilton, M. J., Milne, B. T., Walker, R. S., Brown, J. H., 2007. Nonlinear scaling of space use in human hunter-gatherers. Proceedings of the National Academy of Sciences of the United States of America 104 (11), 4765-4769.

Hart, C. W. M., Pilling, A. R., 1965. The Tiwi of North Australia. Holt, Rinehart and Winston, New York.

Hewlett, B. S., Cavalli-Sforza, L. L., 1986. Cultural transmission among Aka pygmies. American Anthropologist 88 (4), 922-934.

Hitchcock, R. K., Ebert, J. I., 2006. Where is that job at? Hunter-gatherer information systems in complex social environments in the eastern Kalahari Desert, Botswana. In: Whallon, R., Lovis, W. A., Hitchcock, R. (Eds.), Information and its role in hunter-gatherer bands. Cotsen Institute of Archaeology Press, Los Angeles, pp. 133-166. 
Janssen, M. A., Kohler, T. A., Scheffer, M., 2003. Sunk-cost effects and vulnerability to collapse in ancient societies1. Current anthropology 44 (5), $722-728$.

Johnson, J. B., Omland, K. S., 2004. Model selection in ecology and evolution. Trends in Ecology \& Evolution 19 (2), 101-108.

Kaplan, H. S., Hooper, P. L., Gurven, M., 2009. The evolutionary and ecological roots of human social organization. Philosophical Transactions of the Royal Society B: Biological Sciences 364 (1533), 3289-3299.

Keeley, L. H., 1995. Protoagricultural practices among hunter-gatherers. In: Price Douglas, T., Bebaur, A. B. (Eds.), Last Hunters First Farmers. School of American Research Press, Santa Fe, NM, pp. 243-272.

Kelly, R. C., 2000. Warless societies and the origin of war. University of Michigan Press, Ann Arbor, MI.

Kelly, R. L., 1995. The Foraging Spectrum: Diversity in hunter-gatherer lifeways. Smithsonian Institution Press, Washington, D.C.

Kelly, R. L., 2013. The Lifeways of Hunter-gatherers: The foraging spectrum. Cambridge University Press.

Lade, S. J., Tavoni, A., Levin, S. A., Schlüter, M., 2013. Regime shifts in a social-ecological system. Theoretical ecology 6 (3), 359-372.

Lever, J. J., Nes, E. H., Scheffer, M., Bascompte, J., 2014. The sudden collapse of pollinator communities. Ecology letters 17 (3), 350-359.

Marlowe, F., 2010. The Hadza Hunter-Gatherers of Tanzania. University of California Press, Berkeley.

May, R. M., Levin, S. A., Sugihara, G., 2008. Complex systems: Ecology for bankers. Nature 451 (7181), 893-895.

Noy-Meir, I., 1975. Stability of grazing systems: an application of predatorprey graphs. The Journal of Ecology, 459-481.

Odum, E. P., Barrett, G. W., 2002. Fundamentals of Ecology, 5th Edition. Thomson Brooks/Cole, Belmont, CA. 
Olson, M., 1993. Dictatorship, democracy, and development. American Political Science Review 87 (03), 567-576.

Ostrom, E., 2005. Understanding Institutional Diversity. Princeton University Press, Princeton.

Porter, C. C., Marlowe, F. W., 2007. How marginal are forager habitats? Journal of Archaeological Science 34 (1), 59-68.

R Development Core Team, 2008. R: A Language and Environment for Statistical Computing. R Foundation for Statistical Computing, Vienna, Austria, ISBN 3-900051-07-0.

URL http://www.R-project.org

Ray, V. F., 1963. Primitive pragmatists: The Modoc Indians of northern California. University of Washington Press, Seattle, WA.

Scheffer, M., Carpenter, S., 2003. Catastrophic regime shifts in ecosystems: linking theory to observation. Trends in Ecology \& Evolution 18 (12), 648656 .

Scheffer, M., Carpenter, S. R., Lenton, T. M., Bascompte, J., Brock, W., Dakos, V., van de Koppel, J., van de Leemput, I. A., Levin, S. A., van Nes, E. H., et al., 2012. Anticipating critical transitions. Science 338 (6105), 344-348.

Sealy, J., 2006. Diet, mobility, and settlement pattern among holocene hunter-gatherers in southernmost africa. Current Anthropology 47 (4), 569-595.

Smith, B., 2012. A cultural niche construction theory of initial domestication. Biological Theory 6, 260-271.

Smith, E. A., 1988. Risk and uncertainty in the original affluent society: evolutionary ecology of resource sharing and land tenure. In: Ingold, T., Riches, D., Woodburn, J. (Eds.), Hunters and gatherers vol. I: History, evolution, and social change. Berg, Oxford, pp. 222-251.

Staver, A. C., Archibald, S., Levin, S., 2011. Tree cover in sub-saharan africa: rainfall and fire constrain forest and savanna as alternative stable states. Ecology 92 (5), 1063-1072. 
Steward, J. H., 1938. Basin-plateau aboriginal sociopolitical groups. Vol. 120. U.S. G.P.O., Washington.

Thomas, D. H., 1981. omplexity among great basin shoshoneans: The worldsleast affluent foragers. In: Koyama, S., Thomas, D. H. (Eds.), Affluent Foragers: Pacific Coasts East and West C. Nat. Museum Ethnology, Osaka, Japan, pp. $67-87$.

Towner, M. C., Grote, M. N., Venti, J., Mulder, M. B., 2012. Cultural macroevolution on neighbor graphs. Human Nature 23 (3), 283-305.

Wilson, J. A., Acheson, J. M., Metcalfe, M., Kleban, P., JUL 1994. Chaos, complexity and community management of fisheries. Marine Policy 18 (4), 291-305.

Zeder, M., 2012. The broad spectrum revolution at 40: resource diversity, intensification, and an alternative to optimal foraging explanations. Journal of Anthropological Archaeology 31, 241-264. 
Table 1: Variables and definitions

\begin{tabular}{|c|c|c|c|}
\hline Variable & Definition & Estimated process & Reference \\
\hline Ownership & $\begin{array}{c}\text { The presence or absence of formal } \\
\text { territorial ownership }\end{array}$ & Ownership strategies & Binford, 2001 \\
\hline Warfare & Frequency of warfare & Competition for resources & Binford, 2001 \\
\hline Density & Population density & Competition for resources & Binford, 2001 \\
\hline Fishing & $\begin{array}{c}\text { The percent of diet obtained from } \\
\text { aquatic resources }\end{array}$ & Density of resources & Binford, 2001 \\
\hline$N P P$ & 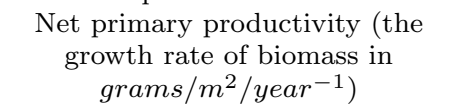 & $\begin{array}{l}\text { Density of terrestrial } \\
\text { resources }\end{array}$ & Grieser et al., 2006 \\
\hline CV Rainfall & $\begin{array}{l}\text { The coefficient of variation of } \\
\text { inter-annual rainfall }\end{array}$ & $\begin{array}{c}\text { Predictability of terrestrial } \\
\text { resources }\end{array}$ & Beck et al., 2004 \\
\hline
\end{tabular}




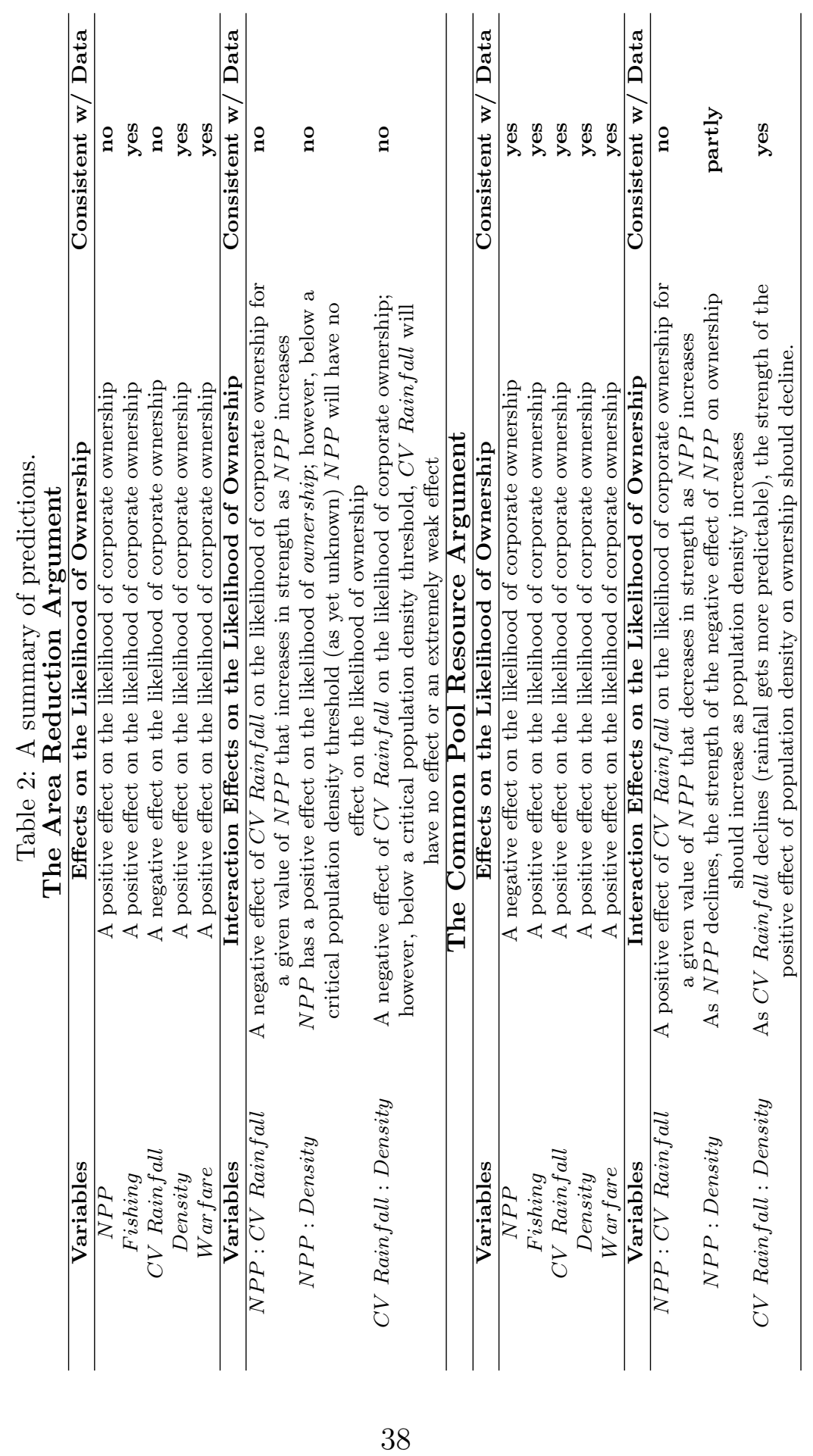


Table 3: Means, standard errors and relative importance ( $\sum$ Akaike weight) of the explanatory variables included in the $95 \%$ confidence set of models. WOwnership=the distance lagged ownership variable. $V=$ vector of residual error from stage 1 regression.

\begin{tabular}{lccc}
\hline Explanatory variable & Coefficient $(b)$ & Std. Error & Importance \\
\hline \hline Intercept & -3.75 & 0.49 & - \\
Warfare & 0.64 & 0.12 & 1.00 \\
Fishing & 0.007 & 0.003 & 0.72 \\
WOwner ship & 4.40 & 1.10 & 1.00 \\
V & -2.75 & 1.78 & 0.73 \\
CV Rainfall : Density & 0.10 & 0.004 & 1.00 \\
NPP : Density & -0.0004 & 0.0004 & 0.58 \\
\hline
\end{tabular}

Table 4: The deviance explained by each variable in the best regression model (i.e., the model with the lowest AIC). Df=degrees of freedom; Deviance=deviance explained by a variable in the regression model. *parameter explains more deviance than would be expected by chance alone at the p.05 level.

\begin{tabular}{lrrrr}
\hline & Df & Deviance & Resid. Df & Resid. Dev \\
\hline NULL & & & 338 & 469.60 \\
WOwnership $^{*}$ & 1 & 137.87 & 337 & 331.73 \\
$V^{*}$ & 1 & 15.00 & 336 & 316.72 \\
Warfare* $_{\text {Fishing* }}^{*}$ & 1 & 27.19 & 335 & 289.53 \\
CV Rainfall : Density & 1 & 18.10 & 333 & 285.30 \\
Density $: N P P$ & 1 & 2.60 & 332 & 267.20 \\
\hline
\end{tabular}



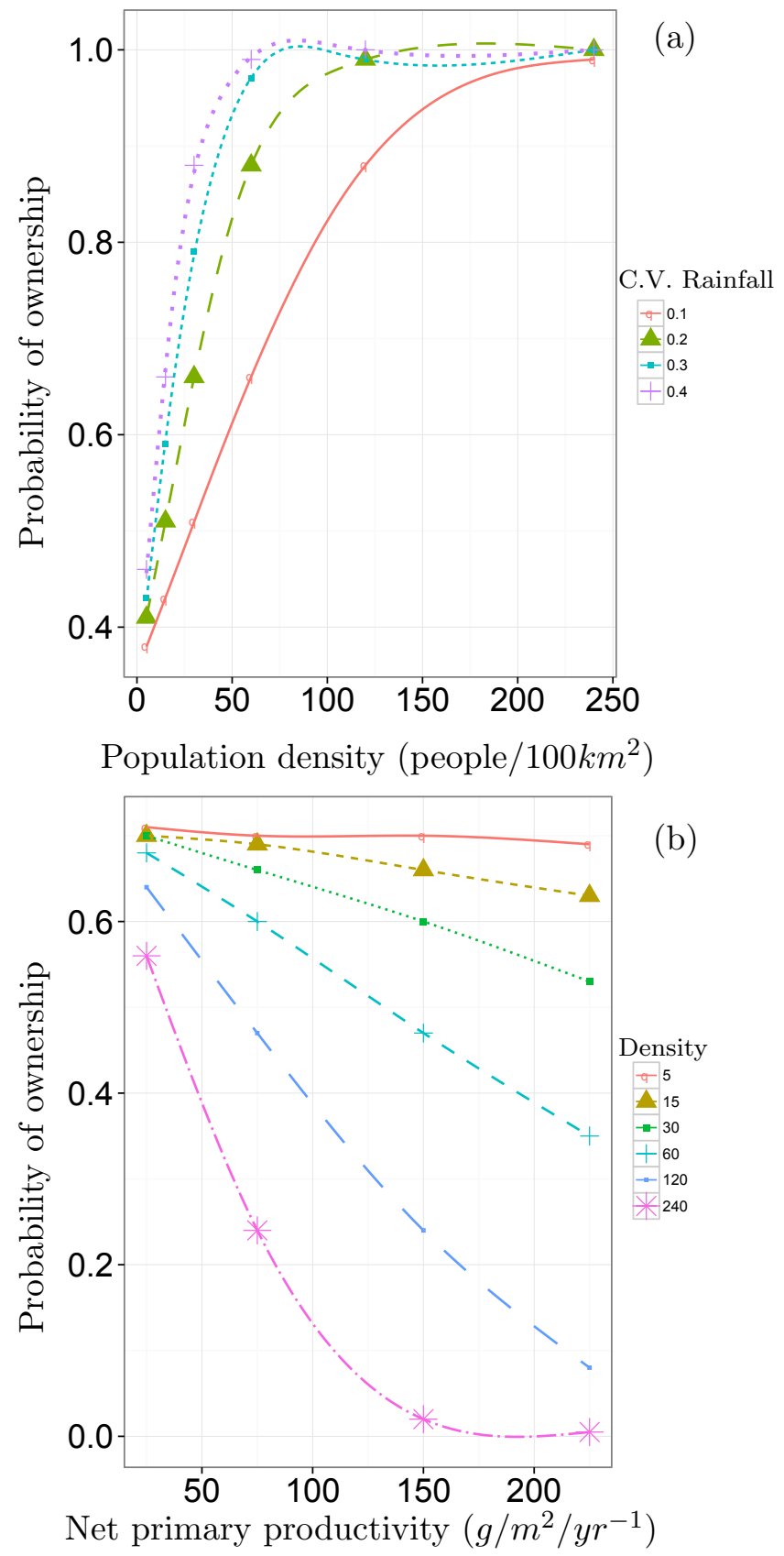

Figure 1: (a)-The effect of population density on the probability of ownership controlling for C.V. Rainfall. The red solid line-C.V. Rainfall is held constant at 0.1 ; green dashed line- 0.2 ; blue long-dashed line-0.3; and the purple dotted line-0.4. (b)-The effect of net primary productivity on the probability of ownership while holding population density equal. Solid red line-population density is held equal at 5; gold dashed line-15, green dotted line-30, light blue medium dashed line-60, dark blue long-dashed line-120; and purple dashed-dot line-240. 